\title{
Prediction Model for the Treatment of Stabilized Oily Wastewater by Modified Induced Air Flotation (MIAF)
}

\author{
Tanun Chalermsinsuwan ${ }^{1,3}$, Ploypilin Romphophak ${ }^{2}$, Nattawin Chawaloesphonsiya ${ }^{1,3}$, \\ and Pisut Painmanakul ${ }^{2,3, a, b, *}$
}

1 International Postgraduate Programs in Environmental Management, Graduate School, Chulalongkorn University, Bangkok, Thailand

2 Department of Environmental Engineering, Faculty of Engineering, Chulalongkorn University, Bangkok, Thailand

3 Center of Excellence on Hazardous Substance Management (HSM), Bangkok, Thailand, Chulalongkorn University, Bangkok, Thailand

E-mail: aPisut.P@chula.ac.th (Corresponding author), bpisut114@hotmail.com

\begin{abstract}
The objective of this study is to propose a prediction model for characterizing stabilized oily-wastewater that has been treated using Induced Air Flotation (IAF) and Modified Induced Air Flotation (MIAF), which is a combination of coagulation and flotation. Wastewater samples containing an anionic surfactant at the critical micelle concentration (CMC) were prepared as the stabilized oily-emulsion. The amount of oil as well as the amount removed was measured using COD. The study shows that the coagulant dosage $\left(\mathrm{C}_{\text {Alum }}\right)$, interfacial area (a), and velocity gradient $(\mathrm{G})$ are the important factors that affect flotation performance. Therefore, the proposed model is based on these parameters in terms of the $C_{\text {Alum }}$ and $a / G$ ratio. The maximum removal efficiency and the reduction of the COD values can be predicted for any of the operating conditions. It was found that predicted oily wastewater efficiency and removal kinetic were compatible with those obtained from experiments. The discrepancy of $5 \%$ between the results from the prediction and the experiment can be found.
\end{abstract}

Keywords: Stabilized oily-wastewater, modified induced air floatation, interfacial area, velocity gradient, prediction model.

ENGINEERING JOURNAL Volume 20 Issue 3

Received 7 October 2015

Accepted 26 November 2015

Published 19 August 2016

Online at http://www.engj.org/

DOI:10.4186/ej.2016.20.3.11 


\section{Introduction}

As a consequence of the widespread use of petroleum products, oily wastewater has become problematic worldwide. The presence of oil alone causes odor, fuming, and other nuisances. It may also cause fouling in conventional wastewater treatment processes [1]; some types of oil, moreover, contain compounds that are toxic or carcinogenic [2]. The one source posing the most problems is lubricant oil, which accounts for $1 \%$ of the petroleum that is produced. Lubricant is commonly used in automobile servicing, material processing, and general machining. It contains various types of hydrocarbons as well as many additives. Used lubricant oils have been classified as a hazardous waste under most regulations, requiring special handling and treatment methods [3].

The common method for the disposal of oily waste is incineration, which heavily depends on the high heat content of the hydrocarbons [2]. In most circumstances, however, the waste exists as oil-in-water emulsions, some of which are highly stable and not easily separated by conventional methods. The presence of water significantly lowers the heat content of the waste, which is problematic in thermal disposal processes. Therefore, a variety of separation techniques have been developed and employed to improve the effectiveness of energy recovery and to increase the possibility of oil recycling [4].

Flotation is a type of gravity separation process using the difference between the density of the air bubbles and the density of the water $[2,5]$. It is widely used in the treatment of wastewater containing particulate matter which is, in this case, oil in the form of small droplets. Currently, two variations of flotation methods are widely applied. The first, dissolved air flotation (DAF), which uses smaller bubbles (30-100 $\mu \mathrm{m}$ in diameter), tends to be more efficient than the second, induced air flotation (IAF), which uses larger bubbles $(700-1500 \mu \mathrm{m})[6,7]$. However, using DAF is subject to several difficulties such as high investment costs, sophisticated equipment, and complex operation. Therefore, IAF has been applied as the alternative that is more suitable for smaller scale operations.

In order to be an effective substitute for DAF, some modifications to the IAF process are needed to enhance its performance. As the result, the modified induced air flotation (MIAF) method incorporates a variety of performance-improving techniques based on simple unit processes that are already employed in the field. Coagulation, for example, is a well-established process that is widely used to destabilize colloidal particles in the wastewater; in this case, the oil droplets are stabilized by the addition of the surfactant $[8,9]$. Various studies have observed that adding a cationic electrolyte as a coagulant helps to enhance the removal efficiencies of IAF and DAF [10,11].

Apart from coagulant addition, operating conditions play significant roles. It was found that the main removal mechanism of induced air flotation (IAF) is the droplet agglomeration that takes place within the wake behind the bubbles' trail [12]. Therefore, the main parameters affecting IAF processes, as found by Leech [13] are the dosage of the coagulant and retention time of the process. Moreover, the size and number of bubbles, which are governed by the air flow rate and air-inducing apparatuses, are also major factors controlling the process [10-14].

In this regard, the performance of IAF and MIAF processes for the treatment of oil-in-water emulsions are governed by several important factors. The numerical relations between these factors and the overall performance, however, are not well established. Therefore, this work is an attempt to propose an empirical model that is derived from experimental data obtained from a batch lab-scale flotation column. The two most important operating parameters, which are the bubbles' hydrodynamic factors and the coagulant dosage, will be incorporated into the model equation. It is important to note that in contrast to some models that have already been proposed [12], this study uses the COD value to represent the amount of oil instead of the number of oil droplets, since its analysis is simpler and more practical.

\section{Materials and Method}

\subsection{Experimental Set-up}

As shown in Fig. 1, the study was conducted within an acrylic flotation column with diameter of $5 \mathrm{~cm}$ and height of $2 \mathrm{~m}$. The working liquid volume of the column was $3 \mathrm{~L}$. Air was bubbled into the column with an air compressor and a porous rigid orifice gas diffuser. For the purpose of controlling the bubbles, the column was equipped with a gas flow meter (New Flow) and an electronic manometer (BIOBLOCK 915PM247). A high-speed camera and a set of computers were used for acquiring and analyzing the 
bubbles' hydrodynamic parameters (Pylon Store and Bubble Measuring Program). The chemical injection point was provided at the bottom of the column. The process was operated at room temperature, the liquid height $\left(H_{L}\right)$ used was $1.5 \mathrm{~m}$, and the sampling point was located $0.2 \mathrm{~m}$ above the gas diffuser.

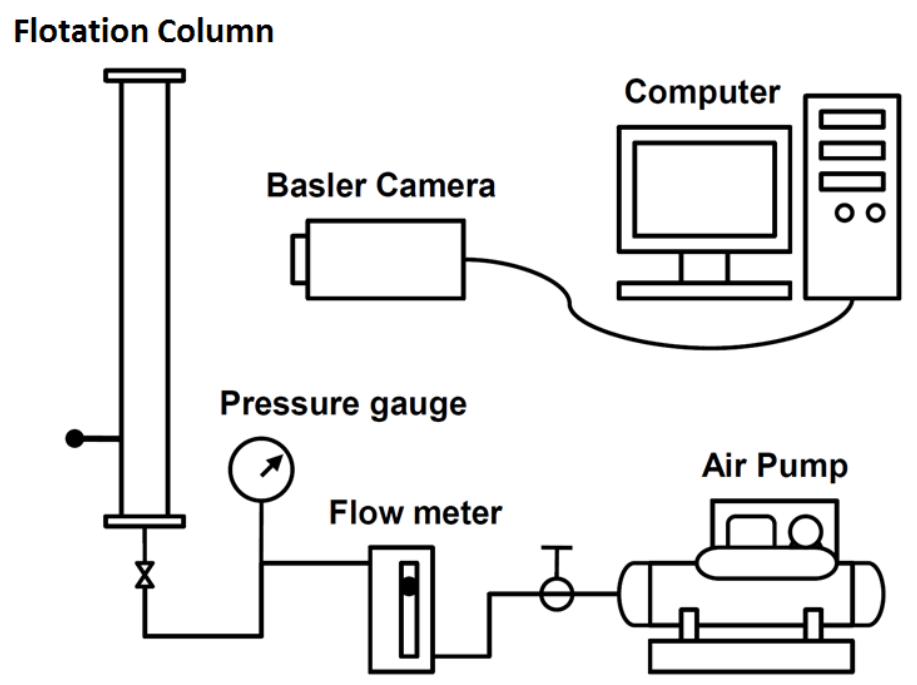

Fig. 1. Experimental schematic diagram.

\subsection{Wastewater Preparation}

The oily wastewater used in the study was synthesized by mixing $300 \mathrm{mg}$ lubricant oil with tap water, giving COD value of $1000 \mathrm{mg} / \mathrm{L}$. This concentration is the one usually found in typical wastewater containing lubricants [4]. Sodium lauryl sulfate was added as the anionic surfactant to create a stable oily emulsion. The amount of surfactant used is $1 \mathrm{mg}$ per liter of prepared water, which is equal to the critical micelle concentration (CMC) of this emulsion. After the mixture was mixed at $300 \mathrm{rpm}$ for 5 minutes, its $\mathrm{pH}$ was adjusted to the desired value using $0.01 \mathrm{~N}$ sodium hydroxide and $0.5 \mathrm{~N}$ sulfuric acid. The $\mathrm{pH}$ values used in the experiments were those providing the highest removal efficiencies in the jar tests.

\subsection{Analytical Parameters}

\subsubsection{Oil removal}

Among the many parameters and analytical methods employed by the numerous studies related to oil removal, chemical oxygen demand (COD) analysis via closed reflux titration method [15] is accepted as a simple, economic, and fairly accurate method to represent the amount of oil in wastewater. It was proved in the preliminary test that the change of COD corresponded to the residual oil content in water by means of fat, oil, and grease (FOG) and total organic carbon (TOC). In the batch system, the percentage of oil removal at any time, $t$, could be expressed as:

$$
\text { Removal efficiency }(\%)=\frac{C O D_{0}-C O D_{t}}{C O D_{0}} \times 100 \%
$$

$\mathrm{COD}_{0}$ and $\mathrm{COD}_{t}$ are the initial COD value and $\mathrm{COD}$ value at any time, respectively. The acquired COD were randomly compared with the FOG and TOC results. Note that the removal efficiency in this study referred to the highest efficiency taken into account the minimum COD obtained from each experiment.

\subsubsection{The bubbles' hydrodynamic parameters and the interfacial area (a)}

The size and rising velocity of the generated bubbles were determined by the photographic method using a high-speed Basler camera (100 images/s). The images taken were then analyzed using an associated analysis 
application. Bubble-size distribution was determined by measuring the diameter of 150 to 200 bubbles. Afterward, the average bubble size in term of the surface-volume (Sauter) mean diameter $\left(D_{B}\right)$ was used to calculate other parameters, including the bubble volume $\left(V_{B}\right)$, bubble surface area $\left(S_{B}\right)$, and bubble interfacial area (a). The number of bubbles produced, i.e., the bubble formation frequency $\left(f_{B}\right)$, was determined by [16]:

$$
f_{B}=Q_{G} / V_{B}
$$

$V_{B}$ is the average bubble volume and $Q_{G}$ is the gas (air) flow rate. The interfacial area (a) is a function of the bubble surface area $\left(S_{B}\right)$, total working volume $\left(V_{\text {Total }}\right)$, bubble formation frequency $\left(f_{B}\right)$, liquid height $\left(H_{L}\right)$, and bubble rising velocity $\left(U_{B}\right)$, which is estimated by measuring the distance a bubble is displaced between two frames. The area is then defined as:

$$
a=N_{B} \times \frac{S_{B}}{V_{\text {Total }}}=f_{B} \times \frac{H_{L}}{U_{B}} \times \frac{S_{B}}{V_{\text {Total }}}
$$

\subsubsection{Velocity gradient $(\mathrm{G})$}

In order to consider the mixing parameter in the IAF and MIAF process, the velocity gradient $(\mathrm{G})$ was calculated using the following formulas [1]:

$$
\begin{gathered}
G=\left(\frac{P}{\mu_{L} V_{L}}\right)^{0.5} \\
P=K Q_{G} \log \left(\frac{h+10.33}{10.33}\right)
\end{gathered}
$$

$\mu_{L}$ is the liquid viscosity and $V_{L}$ is the reactor volume used. The power requirement $(P)$ could be calculated using Eq. (5). Note that $K$ is a constant that equals to 3904 and $b$ is the air discharge pressure expressed in one meter of water.

\section{Results and Discussion}

\subsection{The Effects of $\mathrm{pH}$ on Coagulation}

Prior to the IAF experiments, jar tests were conducted to find the optimal $\mathrm{pH}$ to be used in the other experiments. As shown in Fig. 2, the highest removal efficiencies when alum was used as the coagulant occurred when the $\mathrm{pH}$ value was between 8 and 9. Such a $\mathrm{pH}$ range indicates that sweep floc coagulation was the main destabilizing mechanism [17]. The highest removal efficiency $(61.8 \%)$ was observed at the $\mathrm{pH}$ value of 8 and alum dosage of $400 \mathrm{mg} / \mathrm{L}$. The removal percentages obtained in this study were lower than those obtained by studies measuring turbidity [10]. This suggests that turbidity alone does not actually represent the actual amounts of organic pollutants due to the presence of the dissolved fraction of oil content as well as the dissolved surfactant. However, the change of COD was in accordance to the TOC and FOG results indicating that the variation of oil concentration in the system can be detected by COD. 


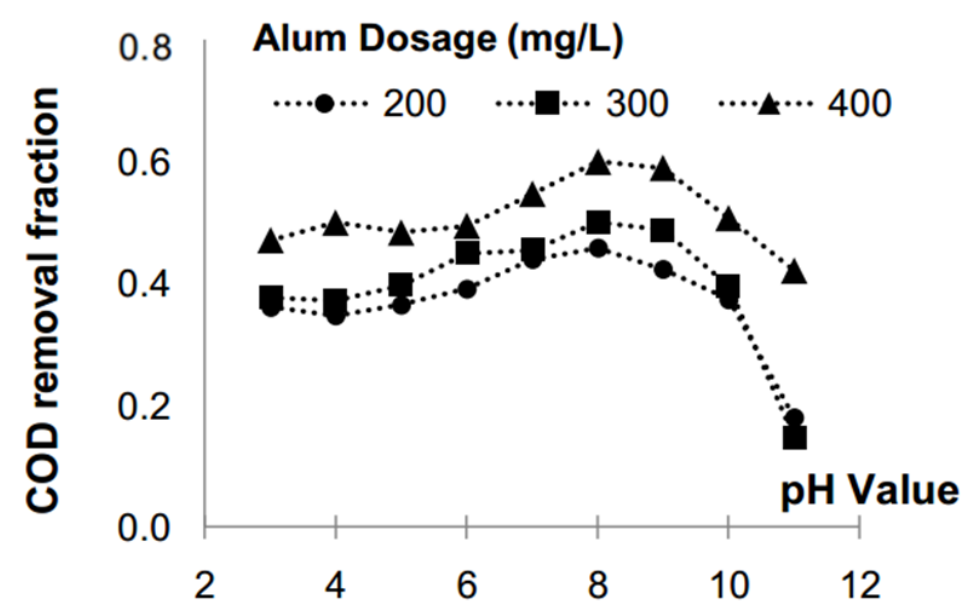

Fig. 2. Jar test results showing COD reduction using different $\mathrm{pH}$ values and coagulant dosages.

\subsection{Removal Efficiency of the MIAF Process}

Removal efficiencies are plotted against air flow rates in Fig. 3 with each line representing a different coagulant dosage $\left(C_{\text {alum }}\right.$ ). It was observed that the efficiency slowly rises when the air flow rate increases and slightly drops after reaching its peak value at the flow rate of $0.3 \mathrm{~L} / \mathrm{min}$ to $0.5 \mathrm{~L} / \mathrm{min}$. Note that the inverted u-shaped relations here are very similar to those obtained in DAF studies [11], in which the rates of removal were plotted against the A/S ratios, and similar trends were also obtained in IAF studies [10]. Moreover, when the same air flow rate was used, higher levels of efficiency could be obtained by adding higher coagulant doses. However, the efficiency levels dropped slightly when a small amount of coagulant was used. This can be explained by the fact that no presence of flocs at the coagulant dosages lower than $100 \mathrm{mg} / \mathrm{L}$. Only enlarged droplets can be seen from the observation under the microscope with 40X magnification. As a result, the sample collection was disturbed resulting in a high possibility that large amount of oil was withdrawn during the sampling. Therefore, the removal efficiency was reduced. On the other hand, little difference was found between the coagulant dosages of $300 \mathrm{mg} / \mathrm{L}$ and $400 \mathrm{mg} / \mathrm{L}$. Such trends could be explained by the fact that adding the coagulant beyond the optimal value results in the restabilization of the oil droplets [17].

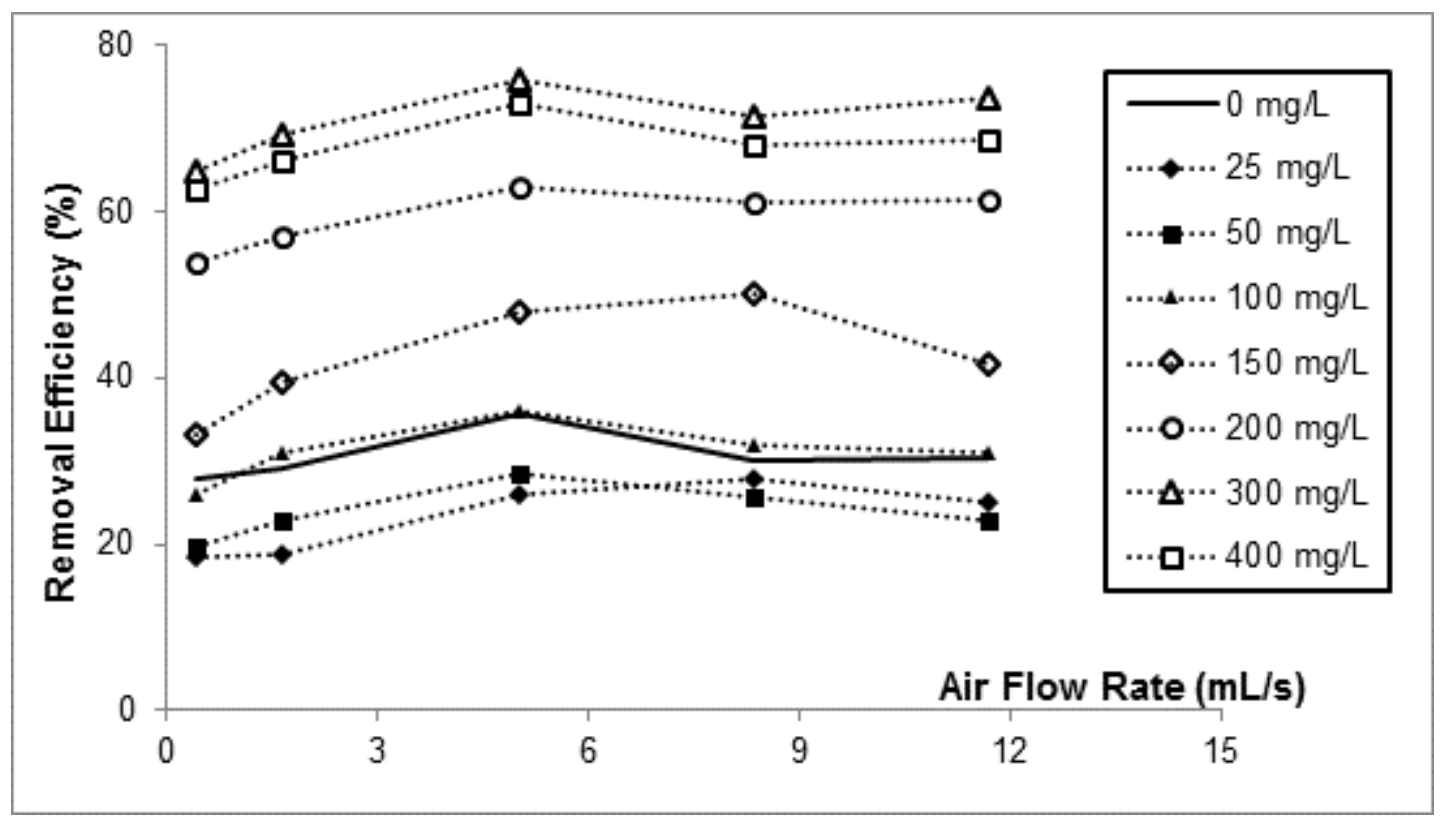

Fig. 3. Removal efficiencies plotted against air flow rates at different coagulant dosages. 


\subsection{Effects of Bubble Hydrodynamic and Mixing Parameters on the Efficiency}

The bubbles' hydrodynamics and mixing parameters were investigated to obtain a better understanding of the relation between the removal efficiency and the gas flow rate. Figs. 4 and 5 show the variations of $D_{B}$, a, and $G$ as the functions of $\mathrm{Q}_{G}$. The close proximity between the data points in Figure 4 implies that the amount of coagulant has little effect on bubble size and the interfacial area, while the velocity gradient depends on the air flow rate and pressure, as shown in Eq. (4) and (5). Theoretically, increasing the interfacial area (a) helps to enhance the removal performance due to the fact that a larger available contact area leads to a higher chance of attachment [18]. As suggested in other reports, when using similar air flow rates, a smaller bubble size is preferred. An appropriate velocity gradient value (G), similarly, is required to obtain a good chemical mixing condition. However, the coalesced particle could still break apart due to intense agitation when the velocity gradient is too high [12].

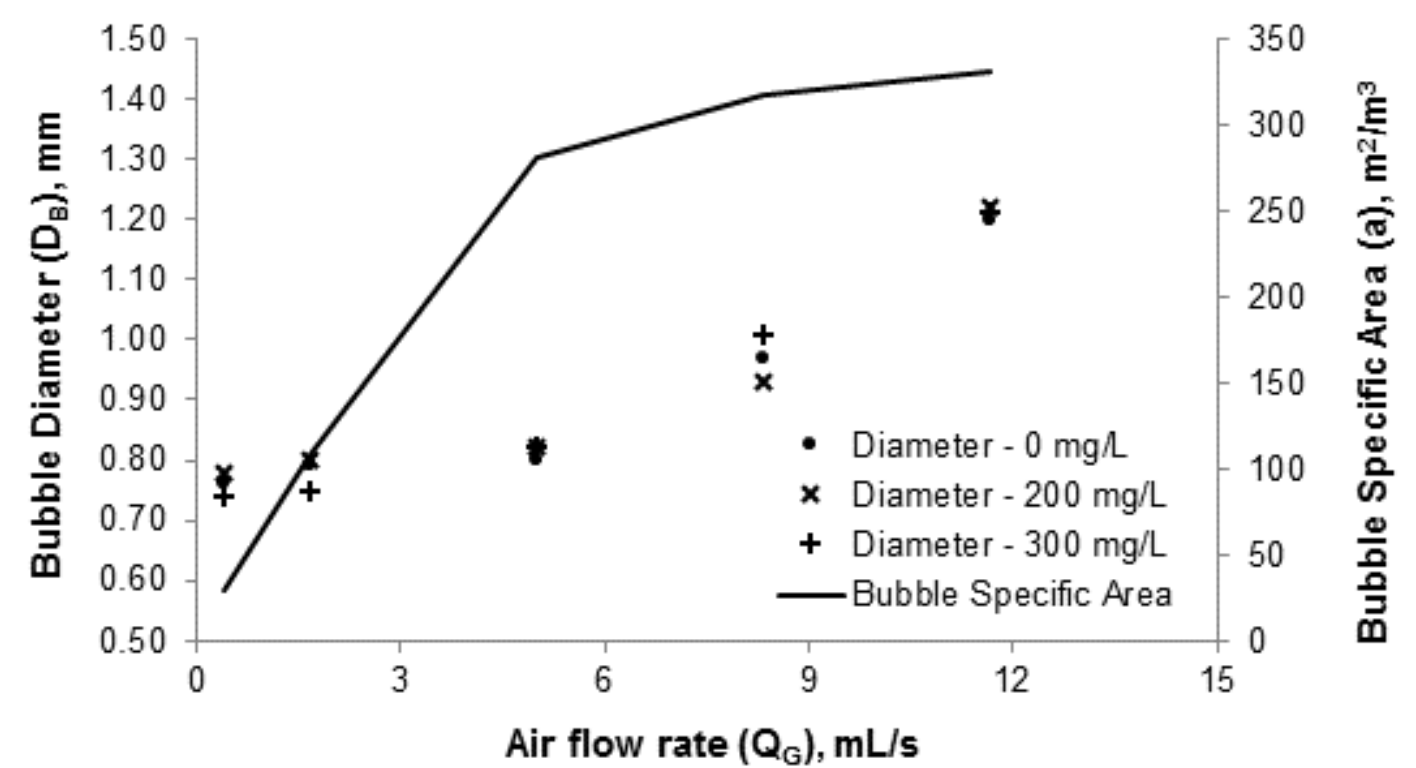

Fig. 4. Average bubble diameters $\left(D_{B}\right.$; represented by dots) and interfacial area (a; represented by lines) at different gas flow rates

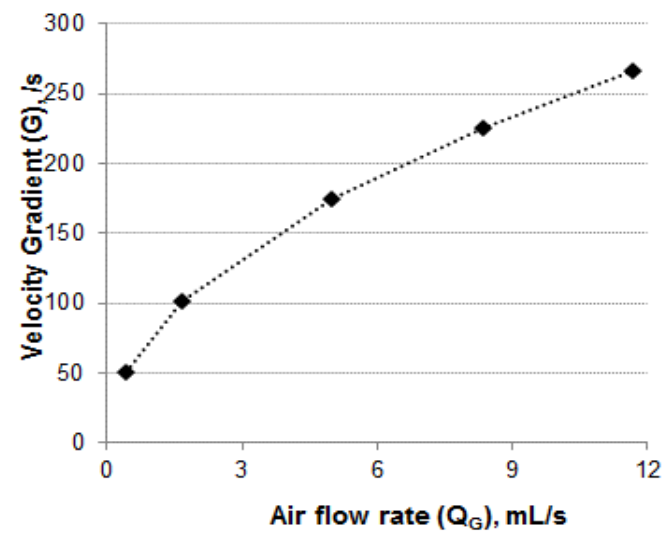

Fig. 5. Velocity gradients at different gas flow rates.

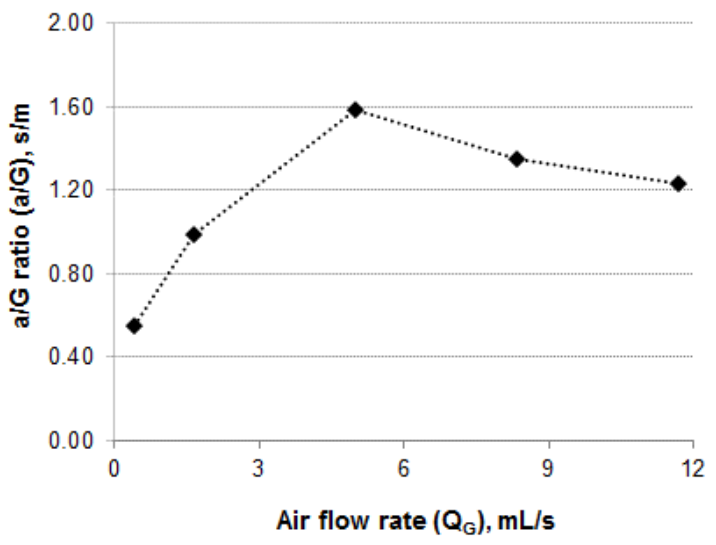

Fig. 6. a/G ratios obtained using different gas flow rates.

In order to make these two parameters into a single term, the ratio between a and $G(a / G)$ is used. The ratios at different air flow rates are presented in Fig. 6 . In this study, the $a / G$ values gradually rose from 0.55 to the maximum value of $1.59 \mathrm{~s} / \mathrm{m}$ starting from the flow rate of $0.3 \mathrm{~L} / \mathrm{min}$, and gradually decreased when higher flow rates were used. This inverted relation is somehow coincidentally similar to the removal 
efficiencies presented in Fig. 3. As expected, when plotted against the a/G ratio in Fig. 7, the removal efficiencies show linear increasing trends with similar slopes (close to ten) and different intercept points. The linear equation could be approximated as:

$$
\% \eta=10(a / G)+I
$$

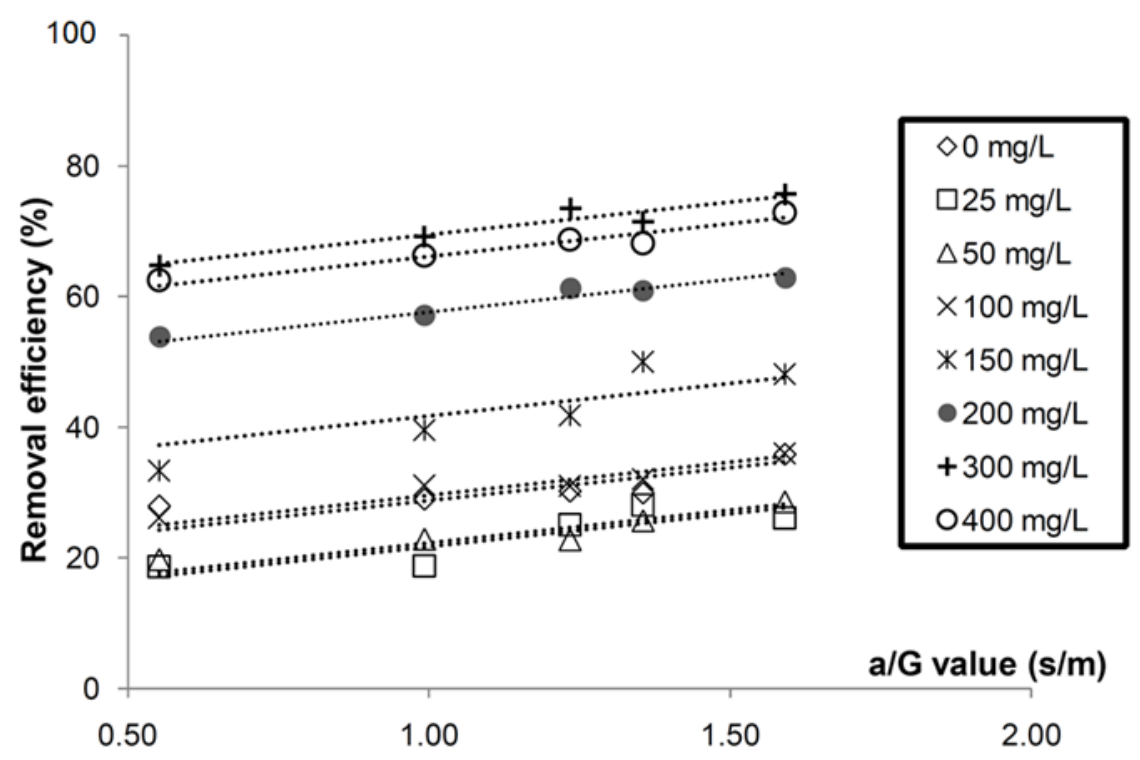

Fig. 7. Apparent linear increasing trend of the efficiency versus the a/G ratio at different coagulant dosages.

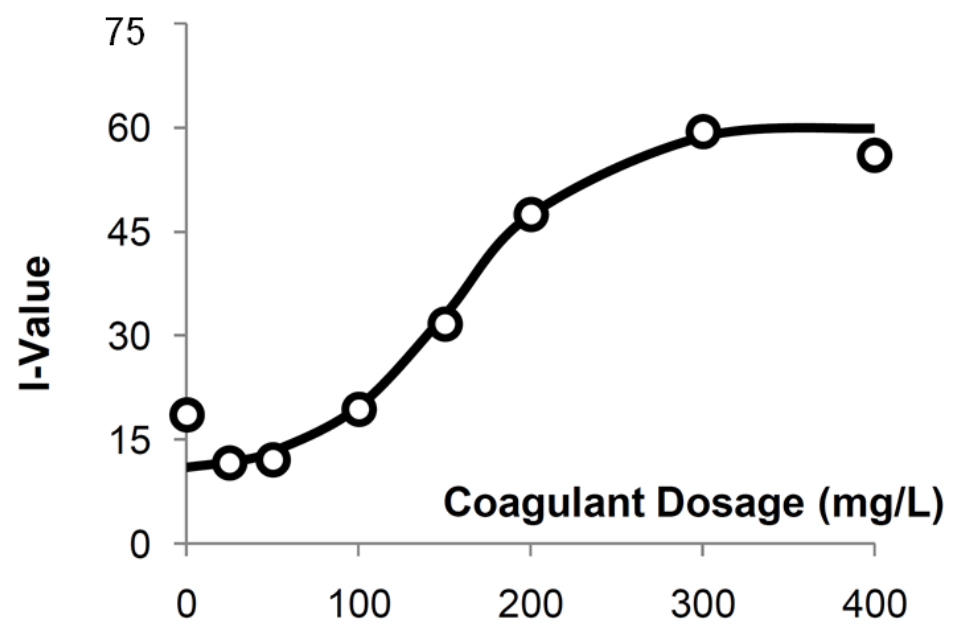

Fig. 8. Values of I, interception points from Fig. 7, plotted against coagulant dosages.

Each interception point, $I$, is plotted against the coagulant dosages in Fig. 8. As previously discussed in Fig. 3, the efficiency gradually rises when the dosage is increased up to $300 \mathrm{mg} / \mathrm{L}$, and it becomes unchanged when dosages above $300 \mathrm{mg} / \mathrm{L}$ are used. Therefore, in this study, this characteristic could be considered an s-curve relation, which is shown by the solid line in Fig. 8. It must be noted that when no coagulant was added (IAF), the calculated I was equal to 11, which is somehow different from the $I=20$ value obtained in the actual IAF experiment.

$$
I=\frac{50 e^{0.025 C}}{50+e^{0.025 C}}+10
$$


Substituting I from Eq. (7) into Eq. (6) gives another equation that could roughly predict the efficiency of the coagulant dosage and $\mathrm{a} / \mathrm{G}$ ratio used.

$$
\% \eta=10(a / G)+\frac{50 e^{0.025 C}}{50+e^{0.025 C}}+10
$$

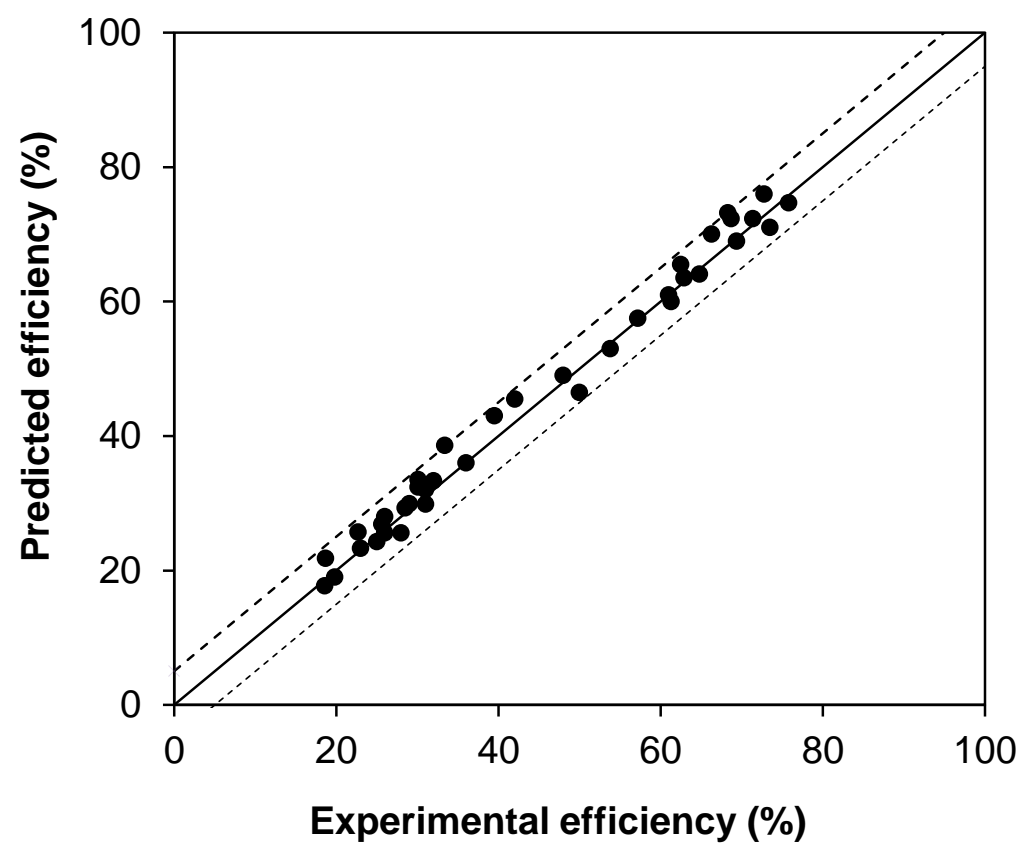

Fig. 9. Comparison between the predicted and actual efficiencies obtained from the process, the dotted lines shows the $\pm 5 \%$ error range.

In Fig. 9, the efficiencies calculated by the equation are compared with those experimentally obtained. The slope of the trendline is close to unity, showing that a good agreement between the predicted and actual efficiencies has been achieved. The differences between the values are within the range of $\pm 15 \%$, which is shown by the dotted lines in the figure. Noted that the value range of the $a / G$ ratio was rather limited in the study due to the type of aerator used. Employing the process under a broader range of $a / G$ values may provide greater insights into the characteristics of the MIAF process.

\subsection{Oil Removal Rate}

Previous studies have described linear trends for treatment efficiency as a function of the a/G ratio and coagulant dose. However, the equations proposed are able to predict only the efficiency, not the oil removal rate. In all cases, the COD is found to exponentially decrease until it reaches the minimum value, where it levels out with only minimal fluctuation, as shown in Fig. 10. The minimum value, COD min, can be thus predicted using the following efficiency equation:

$$
\operatorname{COD}_{\text {min }}=\operatorname{COD}_{0}(1-\eta)
$$

Such a relation is somehow different from the model proposed by Sylvester and Byeseda [12], where the removal rates for all oil droplet sizes were added up to represent the total oil removal rate. However, as indicated in the same work, no significant removal was shown by oil droplets with a diameter smaller than 2 $\mu \mathrm{m}$, which could be further produced by the shear field created by air induction. These residual drops could be the reason explaining the reduction "limit" of the COD value obtained in the experiments, and the fraction of oil droplets smaller than $2 \mu \mathrm{m}$ could be somehow related to the "unremoved" fraction in this work. 


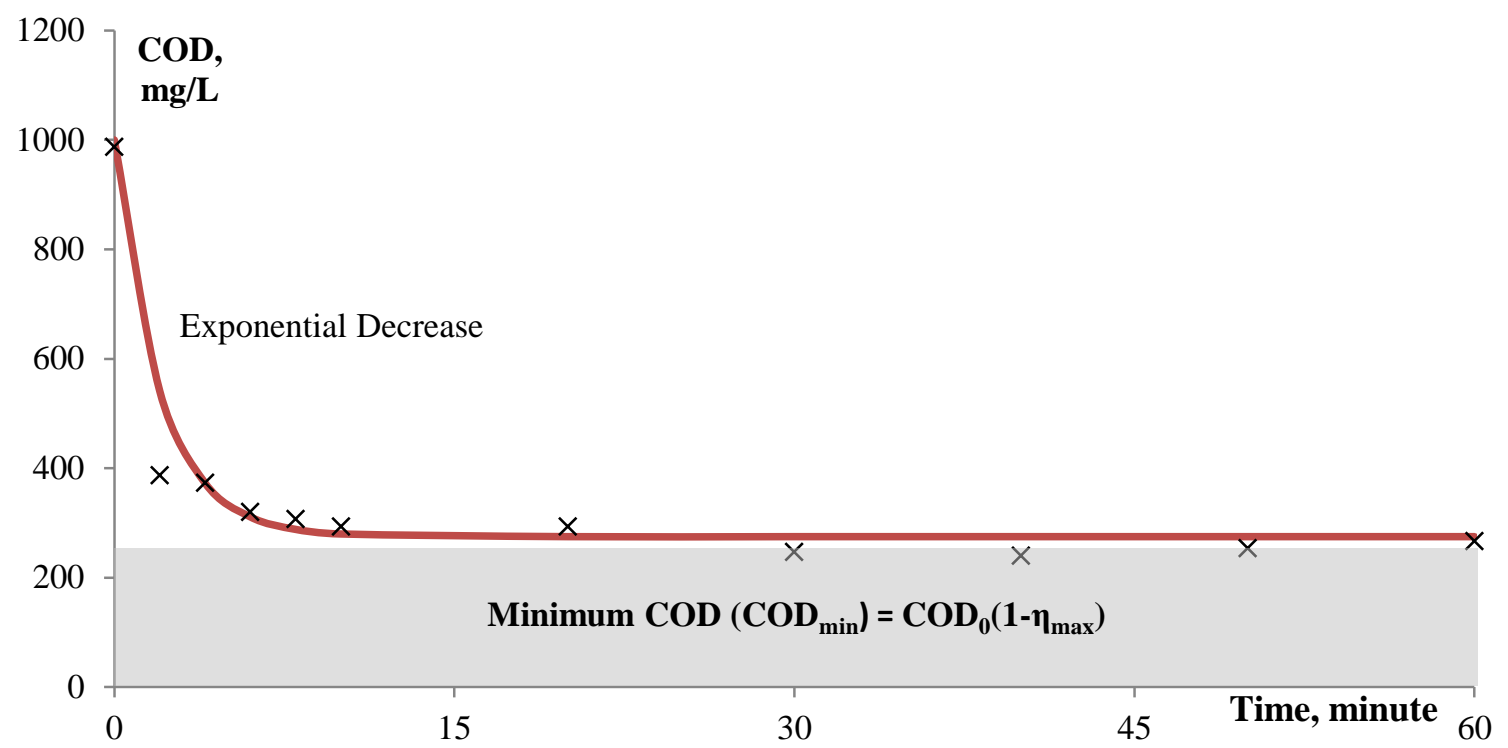

Fig. 10. COD value plotted against time using $\mathrm{C}_{\mathrm{Alum}}=300 \mathrm{mg} / \mathrm{L}$ and $\mathrm{Q}_{\mathrm{G}}=0.3 \mathrm{~L} / \mathrm{m}$ with the line showing the similarity between the data trend and the equation proposed.

In this work, the exponential-like decrease and the minimum limit of oil removal could be described using this equation:

$$
C O D_{t}=C O D_{\min }+C O D^{*} e^{-k t}
$$

where:

$$
C O D^{*}=C O D_{0}-C O D_{\min }=\eta C O D_{0}
$$

Substituting the value of $\mathrm{COD}^{*}$ and $\mathrm{COD}_{\min }$ from Eq. (9) and (11) into Eq. (10) gives:

$$
\operatorname{COD}_{t}=\operatorname{COD}_{0}\left(1+\eta\left(e^{-k t}-1\right)\right)
$$

As the efficiency, $\eta$, is previously defined as a function of the coagulant dosage and a/G ratio in Eq. (9), the value of the COD at any time and given condition could be predicted using this equation. The value of rate constants $(k)$ were obtained by the graphical curve-fitting method and found to vary from one operating condition to another, ranging from $0.4 \mathrm{~min}^{-1}$ to $0.8 \mathrm{~min}^{-1}$. However, neither identifiable trends nor relations were found between $k$ and the two main parameters used. Therefore, the average value of $k$, which is 0.6 $\min ^{-1}$, was chosen in this work. The line in Fig. 10, for instance, was plotted using $\mathrm{k}=0.6 \mathrm{~min}^{-1}$.

\subsection{Comparison of the Predicted and Experimental Values}

By using the proposed equation, the maximum removal efficiency $(\eta)$ and COD value at any time could be predicted for any of the operating conditions. Table 1 gives some examples of the predicted and actual COD values at different times and conditions. The differences between values were found to be less than $5 \%$ in all tested conditions. The difference could be due to the rough estimation of the factor $I$ from the correlation in Eq. (8), which could cause the discrepancy between the predicted and actual results.

In conclusion, the model proposed in this work provides relatively accurate predictions using empirical equations. However, as this model derived from a batch operation, the effects of additional parameters such as the liquid flow rate, flow direction, retention time, and flow condition must be taken into consideration for the continuous flow condition. Moreover, the rate constant in this model is an average value: further experiments or equations may be applied to obtain a better rate prediction. 
Table 1. Predicted COD values compared with those experimentally obtained.

\begin{tabular}{ccccccc}
\hline $\begin{array}{c}\mathbf{C O D}_{\mathbf{0}} \\
\mathrm{mg} / \mathrm{L}\end{array}$ & $\begin{array}{c}\mathbf{C}_{\text {alum }} \\
\mathrm{mg} / \mathrm{L}\end{array}$ & $\begin{array}{c}\text { a/G Ratio } \\
\mathrm{s} / \mathrm{m}\end{array}$ & $\begin{array}{c}\text { Time } \\
\min \end{array}$ & $\begin{array}{c}\text { Predicted COD } \\
\mathrm{mg} / \mathrm{L}\end{array}$ & $\begin{array}{c}\text { Actual COD } \\
\mathrm{mg} / \mathrm{L}\end{array}$ & $\begin{array}{c}\text { \%Increment } \\
\text { \% }\end{array}$ \\
\hline 960 & 25 & 1.23 & 20 & 729 & 760 & 4.1 \\
987 & 100 & 0.99 & 10 & 695 & 720 & 3.5 \\
867 & 200 & 0.55 & 4 & 450 & 467 & 3.6 \\
920 & 400 & 1.36 & 2 & 448 & 427 & 4.8 \\
987 & 300 & 1.59 & 30 & 251 & 247 & 1.7 \\
\hline
\end{tabular}

\section{Conclusions}

The objective of this study has been to propose an empirical model for predicting the performance of the MIAF process in a batch scenario. The ratio of the interfacial area and the velocity gradient $(a / G)$ and coagulant dosage $\left(C_{\text {alum }}\right)$ was applied to account the effects of bubble hydrodynamic phenomena, mixing conditions, and chemical destabilization. The resulting equation shows that the removal efficiency of the MIAF process could be increased by (1) increasing the $a / G$ ratio (linear trend) and (2) increasing the coagulant dosage (nonlinear S-curve trend). In all experiments, the COD was found to exponentially decrease with time to its final value, which is indicated by the removal efficiency.

Despite several limitations, the model could be used as an accurate tool to predict and verify the oil removal percentage by the MIAF process. The error ranges obtained from the prediction were smaller than $\pm 15 \%$ for the efficiency and $\pm 10 \%$ for the removal rate. However, further studies are required to extend the model's applicable ranges, to determine the effects of others parameters that have not been included in the model, and to further investigate the prospect of the $a / G$ ratio as an important operating parameter of the flotation process.

\section{Acknowledgements}

This work was financed by the 90th Anniversary of Chulalongkorn University Fund (Ratchadaphiseksomphot Endowment Fund), the Center of Excellence on Hazardous Substance Management (HSM), and Department of Environmental Engineering, Faculty of Engineering, Chulalongkorn University. This research is also supported by the Rachadaphiseksomphot Endowment Fund Part of the "Strengthen Chulalongkorn University Researcher's Project".

\section{References}

[1] Metcalf \& Eddy Inc., W astewater Engineering Treatment and Reuse, 4th ed. Singapore: McGraw-Hill, 2004.

[2] M. D. Lagrega, P. L. Buckingham, and J. C. Evans, Hazardous Waste Management, 2nd ed. Singapore: McGraw-Hill, 2001.

[3] W. J. Bartz, "Lubricants and the environment," Tribol. Int., vol. 31, no. 1, pp. 35-47, 1998.

[4] Y. Aurelle, "Treatments of oil-containing wastewater," Chulalongkorn University, Bangkok, 1985.

[5] J. Rubio, M. L. Souza, and R. W. Smith, "Overview of flotation as a wastewater treatment technique," Miner. Eng., vol. 15, no. 3, pp. 139-155, 2002.

[6] M. T. Ityokumbul, A. I. A. Salama, and A. M. Al Taweel, "Estimation of bubble size in flotation columns," Miner. Eng., vol. 8, no. 1, pp. 77-89, 1995.

[7] S. Rachu, "Computer program development for oily wastewater treatment process selection, design and simulation," Ph.D. thesis, INSA Toulouse, France, 2005.

[8] G. Rios, C. Pazos, and J. Coca, "Destabilization of cutting oil emulsions using inorganic salts as coagulants," Colloid Surf. A., vol. 138, no. 2, pp. 383-389, 1998.

[9] A. Pinotti and N. R. Zaritzky, "Effect of aluminium sulphate and cationic polyelectrolytes on the destabilization of emulsified waste," Waste Manag., vol. 21, no. 6, pp. 535-542, 2001.

[10] B. Meyssami and A. B. Kasaeian, "Use of coagulants in treatment of olive oil wastewater model solutions by induced air flotation," Bioresour. Technol., vol. 96, no. 3, pp. 303-307, 2005.

[11] K. Bensadok, M. Belkacem, and G. Nezzal, "Treatment of cutting oil/water emulsion by coupling coagulation and dissolved air flotation,” Desalination, vol. 206, no. 1, pp. 440-448, 2007. 
[12] N. D. Sylvestor and J. J. Byeseda, "Oil/water separation by induced air floatation," Soc. Petrol. Eng. J., vol. 20, no. 6, pp. 579-590, 1980.

[13] C. A. Leech, III, S. Radhakrishnan, M. J. Hillyer, and V. R. Degner, "Performance evaluation of induced gas flotation machine through mathematical modeling," J. Petrol. Tech., vol. 32, no. 1, pp. 48 $58,1980$.

[14] A. I. Zouboulis and A. Avranas, "Treatment of oil-in-water emulsions by coagulation and dissolvedair flotation," Colloid Surf. A., vol. 172, no. 1, pp. 153-161, 2000.

[15] Standard Methods for the Examination of Water and Wastewater, American Public Health Association and American Water Works Association and Water Pollution Control Federation, 20th ed., Washington, DC, 1998.

[16] P. Painmanakul, K. Loubière, G. Hébrard, and P. Buffière, "Study of different membrane spargers used in wastewater treatment: Characterisation and performance," Chem. Eng. Process, vol. 43, no. 11, pp. 1347-1359, 2004.

[17] S. Kawamura, Integrated Design and Operation of Water Treatment Facilities. John Wiley \& Sons, 2000.

[18] R. Moosai and R. A. Dawe, "Gas attachment of oil droplets for gas flotation for oily wastewater cleanup,” Separ. Purif. Tech., vol. 33, no. 3, pp. 303-314, 2003. 